\title{
Cómo surgen los conectores: los reformuladores \\ id est, esto es, es decir
}

\author{
JOSÉ LUIS HERRERO INGELMO \\ Universidad de Salamanca \\ «Te quiero en mi paraiso; \\ es decir, que en mi país \\ la gente viva feliz \\ auque no tenga permiso». \\ Mario Benedetti, Te quiero.
}

\section{INTRODUCCIÓN}

El hablante, cuando dice algo, quiere estar seguro de que el oyente comprende cabalmente el sentido de lo dicho. Y por eso no solo construye el texto, sino que intenta organizarlo para orientar al receptor sobre la interpretación del mismo: esa es la función de los llamados marcadores del discurso o conectores.

En la conversación, la reacción física del interlocutor (gestos, mirada...) orienta al autor del enunciado sobre el éxito o sobre el fracaso del acto de comunicación, sobre la correcta o falsa interpretación de lo que dice. En la lengua escrita, hay un feedback, una vuelta atrás, cuando el autor imagina si los futuros lectores pueden o no «comprender» su texto con el sentido que él quiere y decide volver sobre sus pasos. Los conectores que llevan a cabo esta función ponen en relación dos segmentos A/B. El autor vuelve a «formular» el segmento A, con una versión que cree más asequible, más sencilla, más satisfactoria del mismo contenido y que considera «definitiva» (B), que puede afectar al sentido completo del enunciado o al sentido de uno de sus elementos. César Hernández afirma que «el segundo elemento enlazado amplifica el contenido del primero, sin que denotativamente aporte nada nuevo» (1995: 14.4). ${ }^{1}$ Esa amplificación es una especie de «reiteración reflexiva». No hay avance, pero sí una toma de posición clara ante lo que se dice, o sea, una vuelta a una expresión más pensada, más meditada. Los elementos A/B son equivalentes. A este respecto, Catalina Fuentes señala:

Su orientación significativa es la de indicar una relación de equivalencia entre los dos enunciados, contribuyendo a la claridad del discurso. Su estructura es A = B. Esta equivalencia se basa en que B es una explicación de lo que se ha dicho en A. En este segundo enunciado se pretende contribuir al mejore entendimiento de la comunicación por parte del oyente (1987: 174).

Como en otros conectores, los reformulativos han sufrido un proceso más o menos acentuado de gramaticalización, dentro del cambio lingüístico: palabras con significado léxico que van

\footnotetext{
${ }^{1}$ Cita es decir, o sea, esto es, a saber, viene a decir, en otras palabras y los denomina enlaces intraoraciones o concatenadores de equivalencia o de identidad. 
vaciándose para convertirse en elementos gramaticales. En nuestro caso, sin embargo, este proceso no parece completado, puesto que decir y es siguen manteniendo en parte su valor semántico. Parece que estamos ante un caso de gramaticalización imperfecta (decir admite, en algunos casos, variaciones del tipo, podemos decir, digamos...; mantiene su valor de verbo dicendi).

En el caso de id est, esto es y es decir, la reformulación puede ser de diferentes tipos. En los textos doctrinales, a menudo, el sentido literal de una frase debe ser «reinterpretado» -en muchos casos, de lo metafórico a lo real-(reformulación interpretativa), y suele afectar a toda la primera oración -especialmente al verbo como núcleo significativo-. Otras veces, sobre todo en textos legales, el autor desarrolla un elemento que ha sido enunciado de un modo sintético: puede ser un hiperónimo (hijo) o un holónimo (heredad), cuyos hipónimos (Roberto, Rocío) o merónimos (tierras, molinos...) se enumeran y se concretan (reformulación enumerativa). En ocasiones, se trata de establecer estrictas equivalencias entre elementos (fechas, pesos, distancias...) que se citan siguiendo diferentes sistemas o de igualar dos referentes (reformulación de equivalencia). También se puede aclarar un significado, «definir» en definitiva, una palabra o una expresión que el hablante cree nueva y, por tanto, desconocida para el interlocutor (reformulación léxica). En otros casos, es una mera traducción de un texto, de una cita en otra lengua, que el autor imagina opaca para el receptor: es, quizás, el nivel de «reformulación» más elemental, más necesario (reformulación interlingüística). ${ }^{2}$ Siempre hay un alto en el camino del discurso: un momento de reflexión, una mirada atrás.

Después de observar cómo los conectores pasan de cumplir funciones sintácticas en la oración a orientar la interpretación del texto (1), nos detendremos en la aparición de cada uno de los tres conectores de nuestro estudio en los primeros textos de la lengua española: id est (2), esto es (3) y es decir (4).

\section{DE LA SINTAXIS LIBRE AL CONECTOR ${ }^{3}$}

El punto de partida son estructuras compositivas en las que aparecen los conectores cumpliendo funciones sintácticas convencionales; construcciones copulativas que unen una proposición de infinitivo de sujeto y otra de atributo:

decir $x$ es decir que $y$

1. «Decir el Padre de su Hijo ‘Éste es el Hijo mío muy Querido, en el cual Yo mismo a Mí mismo ME SATISFAGO', es decir que EN LOS TRACTOS Y NEGOCIOS QUE TENEMOS CON NUESTRO DIOS, LA POQUEDAD NUESTRA SE PARESCE EN QUE SON MUY BASTANTES NUESTRAS CULPAS PARA ENOJARLE» [Fray Antonio de Guevara, Epístolas familiares, 1521-1543 -reformulación interpretativa doctrinal-].

2. «Y así, en decir El ALMA AQUí QUE LA LLAMA DE AMOR HIERE EN SU MÁS PROFUNDO CENTRO, es decir, que, CUANTO ALCANZA LA SUSTANCIA, VIRTUD Y FUERZA DEL ALMA, LA HIERE Y EMBISTE EL ESPÍRITU SANTO» [San Juan de la Cruz, Llama de amor viva, c 1578-1584 -reformulación interpretativa doctrinal (desarrollo de una imagen)-].

${ }^{2}$ En el análisis de los textos estudiados hemos visto estos diferentes valores (acepciones) de la reformulación. Probablemente se puedan ampliar, pero -en cualquier caso-nos han parecido suficientes para describir el objeto de nuestro estudio.

${ }^{3}$ Los textos están tomados del CORDE y del CREA. 
3. «decir Dios 'Ego OSTENDAM TIBI OMNE BONUM' es decir que LE MOSTRARÁ SU BONDAD» [Fray Antonio de Guevara, Epístolas familiares, 1521-1543 -reformulación interlingüística-]

$$
\text { OR. INFINITIVO es decir y }
$$

4. «Mandar Dios a los hebreos QUE NO SE HAGAN CARACTERES EN LOS BRAzOS es decir que NO IMITEN A LOS SACERDOTES EGIPCIOS» [Fray Antonio de Guevara, Epístolas familiares, 1521-1543 -reformulación doctrinal-].

$$
\text { decir esto es decir y }
$$

5. «Y el decir esto es decir VERDAD, aunque no se pueda dar la demostración dello» [Pedro Simón Abril, Traducción de La ética de Aristóteles, a 1577].

esto es decir que $y$ y que es decir que $y^{4}$

6. «En este día, al principio de la noche, las agujas NORUESTEABAN ?esto es decir que NO ESTABA LA FLOR DE LIS QUE SEÑALA EL NORTE DERECHA HACIA ÉL SINO QUE SE ACOSTABA A LA MANO IZQUIERDA DEL NORTE? y a la mañana NORDESTEABAN que es decir que ACOSTABA LA FLOR DE LIS A LA MANO DERECHA DEL NORTE, HACIA DONDE SALE EL SOL» [Fray Bartolomé de las Casas, Historia de las Indias, c 1527-1561].

7. «ADÁN, INSPIRADO POR DiOS, 'PUSO A CADA COSA SU NOMBRE', Y QUE LO QUE ÉL LAS 'NOMBRÓ, ÉSE ES EL NOMBRE DE CADA UNA?' Esto es decir que A CADA UNA LES VENÍA COMO NACIDO AQUEL NOMBRE» [Fray Luis de León, De los nombres de Cristo, libros I-III, 1583].

Y la diferente escansión esto es o es decir da lugar a los dos conectores (la primera viene avalada por ser traducción literal del latín id est). Esto es un deíctico que apunta al elemento (A) que se quiere explicar, aclarar, concretar, traducir, etc. Se ha dicho que es decir (c'est-à-dire, és a dir) apunta al signo (a lo lingüístico, como el alemán das heisst), y que esto es apunta al referente (a lo ontológico): creo que en este último caso también hay una elipsis del verbo decir (la reformulación siempre es lingüística).

Naturalmente, estamos en una perspectiva sincrónica en la aparición de las diferentes estructuras en el español. Pero en latín ya existía el conector $i d$ est $t^{5}$ y también funcionaba el tipo de construcción arriba señalada.

8. «Superbum est enim, iudices, et non ferendum dicere praetorem in provincia homini honesto, locupleti, splendido, 'Vende MIHI VASA CAELATA'; hoc est enim dicere, 'NON ES DIGNUS TU QUI HABEAS QUAE TAM BENE FACTA SUNT, MEAE Dignitatis ISTA SUnT.' Tu dignior, Verres, quam Calidius?» [Cic. Ver 2.4.45.3].

9. «CUm de comitiis consentiunt rumores, de se quisque dicit 'HAEC FIET', hoc est dicere 'HANC FACIAM'» [Quint.? Decl 252.17.4].

\footnotetext{
${ }^{4}$ Ya en el XV: «Donde Hierónimo habla con la viuda y dice: 'Ruégote que te abaste perder el primero grado de castidad, Y POR EL TERCERO VENISTE AL SEGUNDO, que es decir que POR EL MATRIMONIO VENISTE A LA VIUDEZ; pues guarda el segundo grado de castidad, pues que perdiste el primero'» [Fray Martín de Córdoba, Jardín de nobles doncellas, p 1468].

${ }^{5}$ Las citas latinas están tomadas de $P H I C D \# 5.3$, corpus electrónico que contiene lo esencial de la literatura latina del s. II a. C. al II d. C. (pertenece a The Packard Humanities Institute, 300 Second Street, Los Altos, CA 94022, USA).
} 


\section{LAS PRIMERAS DOCUMENTACIONES DE ID EST (Y A SABER)}

Es el conector latino por excelencia. En español, no se utiliza mucho actualmente, y se ha creído que su escaso uso se debía al influjo del inglés. Está en los documentos notariales latinos con un valor de reformulación enumerativa:

10. «cum OMNIA que ganavimus vel augmentare potuimus, id est, CAVALLOS, EQUAS, BOVES, BACCIS, IUMIENTA» [Anónimo, Fundación de iglesias por el abad Vitulo..., 800].

Este valor de id est será asumido en los textos castellanos por la expresión esto es (a saber) o conviene (a saber) que veremos más adelante. Sin embargo, a lo largo de la Edad Media y de los siglos de Oro ha tenido un uso ininterrumpido. A partir del siglo XIII -sobre todo en los textos científicos-, aparece con frecuencia con el valor de reformulación léxica en cultismos neológicos (la necesidad de aclaración es un síntoma inequívoco de que no está en asimilado aún a la lengua):

11. «de sabor INSIPIDA. id est. SIN SABOR»; «casa de la luna; a la LATRINA \& al banno. id est CAMARA PRIUADA \& a los logares o sse lauan» [Anónimo, Judizios de las estrellas, 1254-1260].

12. «JNFILTRAÇION .id est. JNTRYCAÇION DE VENAS»; «PALIA .id est. ENCUBRE EL DOLOR»; «exsalar .id est. SALLJR FUERA» [Anónimo, Arte complida de cirugía -a 1450-].

13. «En vnguento marçiaton basis es rruda DOMESTICA id est DE CASA vnguento»; «mjenbros RREMOTOS id est ALONGADOS»; «lugar RREMOTO id est LEXOS»; «RRESIDUUM id est LA MATERIA DE LA ENFERMEDAT CONSUMJDA»; "SINGULTO $i d$ est SOLLOÇO»; «FETU id est lo que esta enla VULUA»; «NASO id est la NARIZ» [Anónimo, De las melecinas, a 1500].

También actúa como reformulación léxica (etimológica):

14. «lo llaman JHESU (id est, 'SU SALVADOR')» [Anónimo, Sermonario castellano medieval, 14001500].

Menos frecuente es su uso en la reformulación interpretativa (doctrinal):

15. «Cephas, que sinplemente quiere dezir CABeça, id est, Pedro fue costituido del Sennor por CABEÇA DE TODO EL MUNDO...» [Anónimo, Traducción de la Historia de Jerusalem abreviada de Jacobo, p 1350].

16. «(dize el justo e el bueno: 'Yo desataré toda CARNE -Glosa: id est, LOS DESEOS DE LA CARNE E DE LAS ONRAS MUNDANALES-, ansí lo que repta e anda sobre la tierra como las aves del çielo)» [Anónimo, Sermonario castellano medieval, 1400-1500].

Pero, en general, es más utilizado esto es. El siguiente texto es interesante, pues discrimina perfectamente el uso de estos conectores: id est para el latín; esto es para el español:

17. «Importunus es hombre que nunca está quedo, e es dicho INQUIETUS, esto es, 'NON FOLGADO'. E aún es llamado INPORTUNUS, esto es, 'SIN PUERTO', porque non ha puerto, id est, QUIETEM, esto es, 'QUE NON HA FOLGURA'» [Anónimo, Las Etimologías romanceadas de San Isidoro, p 1450].

En el siglo XV hay un incremento notable de casos: los libros de medicina (Arte complida de la Cirugía, Gordonio, Traducción de la Cirugía Mayor de Lanfranco, De las melecinas) utilizan con frecuencia este conector para explicar los términos especializados (parece claro su uso en el lenguaje científico). 
Las apariciones en el $C R E A$ son escasas; está en Pedro Laín Entralgo, en J. L. Martínez Albertos, en Emilio Romero, ${ }^{6}$ en el cubano Fernando Ortíz y en el mejicano Ignacio Osorio. ${ }^{7}$

Con id est aparece a saber formando una unidad de la que se desgajaron los dos. A saber ya está documentado en los primeros textos en castellano (principios del XII) en enumeraciones de documentos notariales (testamentos, compra-venta...). En las documentaciones del siglo XIII siempre aparece con esto es o conviene delante:

18. «con la heredat que e ni deuo auer en Yguzçquiça, la qual tiene en peynnos don Pero Arceiz de Arroniz por $\mathrm{C}$ morabotinos alfonsis, esto es a saber, pieças e uineas, yermo e poblado con agoas, con yerbas, con montes, con todas sas pertinentias» [Anónimo, Legado de una heredad [Documentos Lingüísticos Navarros], 1212].

19. «quamta heredat auia Domingo Gomzaluez e dona Domenga en Cimanes e in so termino, e despues ouo Roi Fermosino com esa dicta dona Domenga, couiem a saber que terras, uinas, casas, corales, solares, ortos, perales, arbores, eras, fereynanes, pascos, in olleras, pesqueras» [Anónimo Documento de venta [Documentos de la catedral de León], 1239].

A finales del XVII, comienza a aparecer ya solo:

20. «por ser del mundo el número la cifra, / a saber, uno todo y cero nada» [Miguel de Barrios, Poesías, c 1670-1700].

\section{LAS PRIMERAS DOCUMENTACIONES DE ESTO ES}

En los primeros textos, textos notariales, la función más frecuente es encabezar una enumeración. En ocasiones, con $a \operatorname{saber}^{8}$ o acompañado con que:

21. «con la HEREDAT que e ni deuo auer en Yguzçquiça, la qual tiene en peynnos don Pero Arceiz de Arroniz por C morabotinos alfonsis, esto es a saber, PIEÇAS E UINEAS, YERMO E POBLADO CON AGOAS, CON YERBAS, CON MONTES» [Anónimo, Legado de una heredad [Documentos Lingüísticos Navarros], 1212].

Ya en el siglo XIII aparece solo:

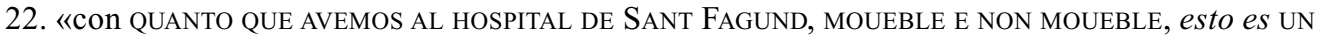
orto Que Compramos de EsteVan DaEnt e de Martín Denís por C MORABedís CON IIII PARES DE CASAS QUE AVEMOS EN VILla de SANT FAGUND» [Anónimo, Fernando Carpentero ofrece sus propiedades al hospital de Sahagún, 1236].

${ }^{6}$ «lo cual determinó que el mencionado diario, id est, Fermín Yzurdiaga, lanzase contra mí toda la potencia agresiva de sus linotipias» [Pedro Laín Entralgo, Descargo de conciencia-1930-1960-(1976)]. «Hay ocasiones en que el redactor también se ve obligado a 'redactar', id est, a 'poner por escrito cosas sucedidas' [J. L. Martínez Albertos, La noticia y los comunicadores públicos, 1978]. «El escudo decía 'Celtiberi id est Robur Hispaniae'». [Emilio Romero, Tragicomedia de España. (Unas Memorias sin contemplaciones), 1985].

${ }^{7}$ El mejicano Ignacio Osorio (1989) cita un texto latino («quae in omnes Novi Testamenti Epistolas traduntur anonyma, id est incerto autore») y el cubano Fernando Ortiz traduce una palabra afrocubana (1975, «el tequina, id est, el maestro»).

8 «don Pero e a todo el conuent d'aquel meismo logar esto es a saber, tres pieças en el termino de Almunia...» [Anónimo, Donación al monasterio de Irache, 1245]. 
Otro valor frecuente es la reformulación interpretativa (doctrinal), sobre todo en los textos bíblicos:

23. «Tú, enemigo, que destroist las ciudades \& fincaron yermas fasta la fin, PEREÇRÁ LA REMEMBRANÇA D'ELLOS, esto es, QUE PEREÇRÁS TÚ, MAS DIOS DURA SIEMPRE JUDGANDO DERECHO» [Herman el Alemán, Traslación del Psalterio, c 1240-1272].

24. «Este thesoro [304c] thenemos en UASOS FECHIZOS [esto es, en LOS NUESTROS FLACOS CUERPOS]» [Anónimo, El Nuevo Testamento según el manuscrito escurialense I-j-6, a 1260, muy frecuente en este texto].

En la obra alfonsí predomina lo que denominamos reformulación léxica. Hay que recordar que es la primera vez que la lengua española necesita acoger un elevado número de préstamos de otras lenguas en el gran proceso de traducción de la cultura oriental. Los neologismos de Alfonso X son neologismos de necesidad: se refieren a nuevas realidades que necesitan de forma particular.

Así se «traducen ${ }^{9}$ palabras cultas ( «NEGLIGENCIA esto es DESDEN»; «BENIGNO esto es DE BUEN ALMA») ${ }^{10}$. O adjetivos neológicos («las noblezas YMPERIALES esto es QUE PERTENESCEN A EMPERADOR»; «sentencia CAPITAL esto es QUE MURIESSE POR ELLO»; «las visiones FANTÁSTICAS, esto es ANTOJADIZAS E MINTROSAS». Y, más raramente, verbos («FILOSOFAR, esto es, CONTENDER EN LOS SABERES DE LA FILOSOFÍA»; «ABREVIÓ, esto es ENCORTÓ»).$^{11}$

A veces la reformulación afecta a un tipo de manera de fechar que no es el normal: las calendas ( «Lunes .XVJ. DIAS ANTES DE LAS CALENDAS DE AGOSTO esto es XVJ. DIAS POR ANDAR DEL MES DE JULIO»), las ferias («Et enel dia de QUARTA FERIA esto es en el MiÉRCOLES») o las referencias al Zodíaco («ENTRA EL SOL EN EL SIGNO DEL CARNERO, e esto es XVIII DÍAS ANDADOS D'ESSE MES»). Este tipo de reformulación afecta también a gentilicios («Mas essos VLTRAMONTANOS esto es LOS DE ALEND DE LOS MONTES»; «los GALLOS esto es los FRANÇESES») y a topónimos («GALLIA GOTICA esto es Francia»; «GALLIA COMATA esto es LA CABELLADURA O AJUMADA; GALLIA BELGICA esto es DEL NOMBRE DE LA SU YENT»).

\section{LAS PRIMERAS DOCUMENTACIONES DE ES DECIR}

Manuel Casado se extraña de que Hayward Keninston (1937) no incluya en su monografía sobre la sintaxis del XVI el conector es decir, frecuente en la prosa (sobre todo, en San Juan). Después, cita las variaciones frecuentes del tipo como si dijera, que quiere decir, que es como decir, como si dijese, o por mejor decir... y concluye:

La presencia insistente del verbo decir en todas ellas es anuncio del éxito de difusión de que gozará, siglos después, el galicismo es decir (1996: 322).

\footnotetext{
${ }^{9}$ Los textos citados pertenecen a la Estoria de España, II (1270-1284) y a la General Estoria. Primera parte (c 1275).

${ }^{10}$ Otra manera de «traducir» los neologismos, además de o sea, o, conviene a saber, a saber, es lo que se ha denominado "ditología sinonímica», ya utilizada por Villena y por Mena en el XV y muy frecuente en el Renacimiento: el segundo sinónimo es la traducción del primero: «deprecación y ruego», «iniquidad y maldad», «pugnir y castigar»... Cf. José Luis Herrero (1999).

${ }^{11}$ También con sentido metafórico: «Offrecio aquella tierra al ALTO. esto es a DIOS».
} 
Y utiliza como testimonio textos del XVIII (Feijoo, Moratín o el purista Forner). Después afirma su consolidación en el XIX. Pero la documentación que nos proporciona el CORDE parece contradecir el carácter de galicismo. Quizás el francés en el XVIII incrementó su uso, pero los documentos que manejamos aparecen en el XV y aumentan en los siglos de Oro.

En francés está documentado -Trésor de la langue française-en 1306 (con sentido de precisión, Royaux lignages), y el 1866 (con el de rectificación). C'est-à-dire que data de 1495 (Le Roman de Jehan de Paris). El tipo de textos, que vamos a citar, no parece recibir influencia francesa: son en muchos casos tratados religiosos.

La primera documentación es reformulación de un sintagma:

25. «Pues que ya es dicho y largamente recontado de la criación de la primera mujer, que fué maravillosa y llena de grandes misterios, razón será, según la orden que al comienzo pusimos, que digamos de la GENERACIÓN DE LAS OTRAS MUJERES, es decir, de LA GENERACIÓN NATURAL DE VARÓN Y MUJER» [Fray Martín de Córdoba, Jardín de nobles doncellas, p 1468].

Aparecen reformulaciones interpretativas en textos científicos y en textos doctrinales:

26. «sobre todo me ha fatigado en este tiempo presente en el que han ocurrido y ocurren cada día los dichos dolores, en los cuales he procedido algunos días canónicamente COMO LOS AUTORES Y DOCTORES MANDAN: es decir, SANGRANDO EN PRINCIPIO DE LA PARTE CONTRARIA, sacando sangre según el henchimiento y a tenor de la virtud, teniendo en cuenta las otras particularidades...» [Diego Álvarez Chanca, Tratado nuevo no menos útil que necesario en que se declara de qué manera se ha de curar el mal de costado epidémico, 1506].

27. «a esta Iglesia, tu esposa, TE CONSAGRASTE, dejando las otras cosas; es decir, TE LIGASTE A DiOs mediante la fe» [Fray Bartolomé de las Casas, Tratado sobre los indios que han sido hechos esclavos [Tratados de 1552], 1552].

28. «Luego decir a Dios: Señor, VENGa A nOS EL TU REINO; es decir: SuPlicÁmoste, QUE ANSí COMO TÚ DE DERECHO ERES REY Y SEÑOR DE NUESTRAS ALMAS, LO SEAS DE HECHO, PUES ESTÁ EN TU MANO» [Felipe de Meneses, Luz del alma cristiana, 1555].

29. «y SUS PISADAS EN MUCHAS AGUAS Y QUE POR ESO 'NO SERÁN CONOCIDAS', es decir, QUE ESTE CAMINO DE IR A DiOS ES TAN SECRETO Y OCULTO PARA EL SENTIDO DEL ALMA COMO LO ES PARA EL DEL CUERPO EL QUE SE LLEVA» [San Juan de la Cruz, Noche oscura, c 1578].

También aparece la reformulación de equivalencia en cuanto al tiempo en textos científicos y doctrinales:

30. «estas purgaciones se deben dar DE NOCHE, es decir, DE GRAN MADRUGADA» [Diego Álvarez Chanca, Tratado nuevo no menos útil que necesario en que se declara de qué manera se ha de curar el mal de costado epidémico, 1506].

31. «la eterna condenación de los OPRESORES, es decir, de los ESPAÑOLES»; «peligro de condenación para los OPRIMIDOS, es decir, para los INDIOS» [Fray Bartolomé de las Casas, Tratado sobre los indios que han sido hechos esclavos [Tratados de 1552], 1552].

Con menos frecuencia aparecen en la enumeración y en la traducción:

32. «las ARMAS de nuestra milicia no son las materiales, sino EL PODER DE DIOS, es decir, LAS AMONESTACIONES, LA ORACIÓN DEVOTA Y, CONTRA LOS PERTINACES, LA SENTENCIA DE EXCOMUNIÓN» 
[Fray Bartolomé de las Casas, Tratado sobre los indios que han sido hechos esclavos [Tratados de 1552], 1552].

33. «decir después AMÉN, es decir: ASÍ SE HAGA, Señor» [Felipe de Meneses, Luz del alma cristiana, $1555]$.

Alterna con la forma (que) es decir que, que puede expresar también una reformulación léxica, una traducción o una reformulación doctrinal:

34. «Ésta se divide en dos partes: la una es por la cual se sabe bien constituir e poner las leyes que son convenientes al bien público, y ésta llama el Philósopho, 6, Ethicas, capítulo $9^{\circ}$, ARCHITECTÓNICA, que es decir PRINCIPAL Y QUE MANDA A LAS OTRAS» [Fray Antonio de Guevara, Epistolas familiares, 1521-1543].

35. «Fuero es que quando el padre o la madre hazen testamento y dejan su heredad para aniversario o para ALMARIO, que es decir para SU ALMA O PIA CAUSA...» [Anónimo, Fuero reducido de Navarra, a 1530].

36. «todas estas gentes, A TOTO GENERE -que es decir: COMÚNMENTE Y CUASI TODOS y que por maravilla falta en algunos, tienen los sentidos exteriores y interiores» [Fray Bartolomé de las Casas, Historia de las Indias, c 1527-1561].

37. «DATE, ET DABITUR VOBIS, que es decir: DAD, Y DAROS HAN» [Fray Luis de Granada, Libro de la oración y meditación, 1554].

38. «TUS CABELlOS COMO LA PÚRPURA, Ó CARMESí DEL REY, ASIDA Á LOS MADEROS, Ó ARTESONES. Que es decir que SUS CABELLOS DE LA ESPOSA EN SU LINDEZA Y HERMOSURA SON SEMEJANTES Á LAS FLOCADURAS DE SEDA» [Fray Luis de León, Exposición del Cantar de los Cantares, c 1561].

\section{CONCLUSIONES}

El orden de aparición de los conectores estudiados es el siguiente: id est, a saber (es a saber y conviene a saber) están ya en los primeros textos; en el XIII aparece esto es (con variantes como esto es a saber)... Es decir es de principios del XVI. ${ }^{12}$ No parece tan claro, pues, que es decir sea un préstamo del francés y que id est lo sea del inglés, aunque es posible que ambas lenguas influyeran en sus usos (general en el primer caso; muy escaso en el segundo).

La reformulación enumerativa es la que aparece en primer lugar, con id est y con esto es (menos frecuentemente con es decir). La interpretativa es característica de los textos doctrinales en los que el convencimiento ideológico del receptor desempeña un papel fundamental. La léxica es característica de los textos científicos que ante el uso de neologismos pretender garantizar su comprensión. Le enumerativa y la de equivalencia están menos marcadas respecto del tipo de texto. Finalmente, la reformulación interlingüistica aparece cualquier texto que recoja una cita en lengua extranjera, normalmente en textos religiosos con citas bíblicas en latín.

Ahora que está en marcha el proyecto filológico más importante de los últimos años, el diccionario histórico, sería bueno que quedara constancia en él de esa sucesiva aparición

12 O sea aparece, como marcador, en la segunda mitad del siglo XVI. Figura por primera vez como reformulación interlingüística: «Es costumbre antigua entre gente bien criada viendo a uno estornudar hazer algún sentimiento de ayudarle diziéndole, Deus teCuM o, 'Dios te ayude', o sea, 'Dios CON VUESTRA MERÇED', conforme a la qualidad de la persona...» (Sebastián de Horozco, Libro de los proverbios glosados, 1570-1579). En este caso, Manuel Casado (1996: 327) tiene razón cuando considera o sea propio del XVIII (solo hay ocho casos de uso como conector en los siglos de Oro). 
de los valores de los conectores. Por ejemplo, en es decir, se pueden recoger las variantes previas y escoger una cita adecuada de cada una de ellas y la aparición de cada una de las acepciones (tipos de reformulación). Se puede ver así el movimiento del cambio lingüístico: de las estructuras compositivas a las secuencias conectoras. Las acepciones (en este caso, «las funciones textuales») pueden ir ordenadas cronológicamente: 1) interpretativa ( $p$ 1486) 2) de equivalencia (1526) 3) enumerativa (1552) y 4) interlingüística (1555). De esta forma, podemos ver cómo se va construyendo el universo significativo de los conectores en esa sinfonía de funciones que los hacen tan versátiles, tan heterogéneos, pero tan atractivos para la investigación lingüística.

\section{REFERENCIAS BIBLIOGRÁFICAS}

BACH MARTORELL, Carme (1996): «Reformuladores ¿una operación argumentativa aséptica?», Sendebar, 7, pp. 255-271.

Casado Velarde, Manuel (1991): «Los operadores discursivos 'es decir', 'esto es', 'o sea' y 'a saber' en español actual: valores de lengua y funciones textuales», Lingüistica Española Actual, XIII, pp. 87-116.

— (1996): «Notas sobre la historia de los marcadores textuales de explicación 'es decir' y 'o sea'», en M. Casado Velarde et alii, eds., Scripta Philologica. Homenaje a M. Taboada, A Coruña, Universidad de A Coruña, I, pp. 321-328.

Fuentes RodríGuez, Catalina (1987): Enlaces extraoraciones, Sevilla, Alfar.

— (1993): «Conclusivos y reformulativos», Verba, 20, pp. 171-198.

HERnÁNDEZ Alonso, César (1995): Gramática funcional del español, Madrid, Gredos.

GAlÁN Rodríguez, Carmen (1998): «La dimensión explicativa y deóntica de los conectores 'o sea', 'es decir'», Anuario de Estudios Filológicos, 21, pp. 84-104.

GAUlmyn, Marie-Madeleine de (1987): «Reformulation et planification métadiscursives», en J. Cosnier y C. Kerbrat-Orecchioni, dirs., Décrire la conversation, Lyon, Presses Universitaries, pp. 167-198.

GüLICH, Elisabeth y Thomas KотsCHI (1983): «Les marqueurs de la reformulation paraphrastique», Cahiers de Linguistique Française, 5, pp. 305-351.

HERRERO, José Luis (1999): «La amplificatio verborum: sinonimia y traducción en un texto renacentista, 'El Espejo del Pecador' (1553), de fray Juan de Dueñas», en J. Fernández et alii (eds.), Lingüistica para el Siglo XXI (Actas del III Congreso de Lingüistica General. Universidad de Salamanca), Salamanca, Universidad de Salamanca, II, pp. 913-918.

ImBs, Paul y Bernard Quemada (1971-1994), Trésor de la langue française, Centre national de la recherche scientifique, Institut national de la langue française. http://atilf.atilf.fr/tlf.htm.

Keniston, Hayward (1937): The Syntax of Castilian Prose (The Sixteenth Century), Chicago, The University of Chicago Press. 
LóPez Alonso, Covadonga (1990): «El discurso y el conector reformulativo 'es decir'», Revista de Filología Románica, 7, pp. 87-97.

MurAt, Michel y Bernard CARTIER-BRESSON (1987): «'C'est-à-dire' ou la reprise interprétative», Langue Française, 73 (La reformulation du sens dans le discours), pp. 5-15.

Real Academia Española: Banco de Datos (CORDE) [en línea]: Corpus diacrónico del español, $<$ http://www.rae.es $>$ [10-15 de Abril de 2006].

Real ACAdEMia Española: Banco de Datos (CREA) [en línea]: Corpus de referencia del español actual. $<$ http://www.rae.es> [10-15 de Abril de 2006].

RosSARI, Corinne (1994): Les operations de reformulation, Berna, Peter Lang.

Roulet, Eddy (1987): «Complétude interactive et connecteurs reformulatifs», Cahiers de Linguistique Française, 8, pp. 111-139. 